Section II. Systems and programs

\title{
A mathematical model of continuous arterio-venous hemodiafiltration (CAVHD)
}

\author{
E. Akcahuseyin ${ }^{1}$, H.H. Vincent ${ }^{2}$, F.J. van Ittersum ${ }^{2}$, W.A. van Duyl ${ }^{1}$ \\ and M.A.D.H. Schalekamp ${ }^{2}$ \\ ${ }^{1}$ Department of Biomedical Physics and Technology and ${ }^{2}$ Department of Internal Medicine 1, Erasmus University Rotterdam. \\ Rotterdam, The Netherlands
}

\begin{abstract}
Continuous arterio-venous hemodiafiltration (CAVHD) differs from conventional hemofiltration and dialysis by the interaction of convection and diffusion, the use of very low dialysate flow rates and by the deterioration of membrane conditions during the treatment. In order to study the impact of these phenomena on diffusive transport, we developed a mathematical model of the kinetics of CAVHD solute transport from plasma water to dialysate. The model yields an expression of the diffusive mass transfer coefficient, $K_{\mathrm{d}}$, as a function of blood, filtrate and dialysate flow rates and solute concentrations, which can be measured in the clinical setting. This paper gives a description of the model derivation. $K_{\mathrm{d}}$ is demonstrated to vary depending on dialysate flow and duration of treatment.
\end{abstract}

Continuous arterio-venous hemodiafiltration; Mass transfer; Kinetics; Mathematical model

\section{Introduction}

Continuous arterio-venous hemofiltration (CAVH) is a form of renal replacement therapy that is used in the intensive care unit. It is characterized by the use of a small surface highly permeable hemofilter, spontaneous blood flow and spontaneous ultrafiltration. With CAVH solute transport occurs by convection. Continuous arterio-venous hemodiafiltration (CAVHD) is a combination of CAVH with slow dialysis (Fig. 1). In CAVHD, therefore, solute transport occurs both by convection and by diffusion $[4,7,10]$.

While, generally, the rate of solute removal by convection is easily calculated from the rate of

\footnotetext{
Correspondence: Dr. W.A. van Duyl, Department of Biomedical Physics and Technology, Erasmus University Rotterdam, Faculty of Medicine, P.O. Box 1738, 3000 DR Rotterdam, The Netherlands.
}

ultrafiltration, there is little insight in the determinants of diffusive solute transport with CAVHD. CAVHD differs in several respects from conventional hemodialysis and hemodiafiltration. First, dialysate flow rate $(10-30 \mathrm{ml} / \mathrm{min})$ is very low compared to blood flow rate $(100-250 \mathrm{ml} / \mathrm{min})$ and as a consequence the change in dialysate solute concentration over the length of the filter cannot be taken to be linear. Second, with prolonged use of the filter, hydraulic permeability of the membrane decreases, presumably due to clotting and protein boundary layer formation. This is reflected in a gradual fall in the rate of ultrafiltrate production $[4,10]$. The same phenomena are expected to impair diffusive permeability as well. As a consequence, existing models of hemodialysis or hemodiafiltration [1,3,5,9] do not apply. Recently Pallone et al. attempted to describe solute kinetics in CAVHD in mathematical terms [8]. In their article, however, no model equations are given. Furthermore, numerical data were ob- 


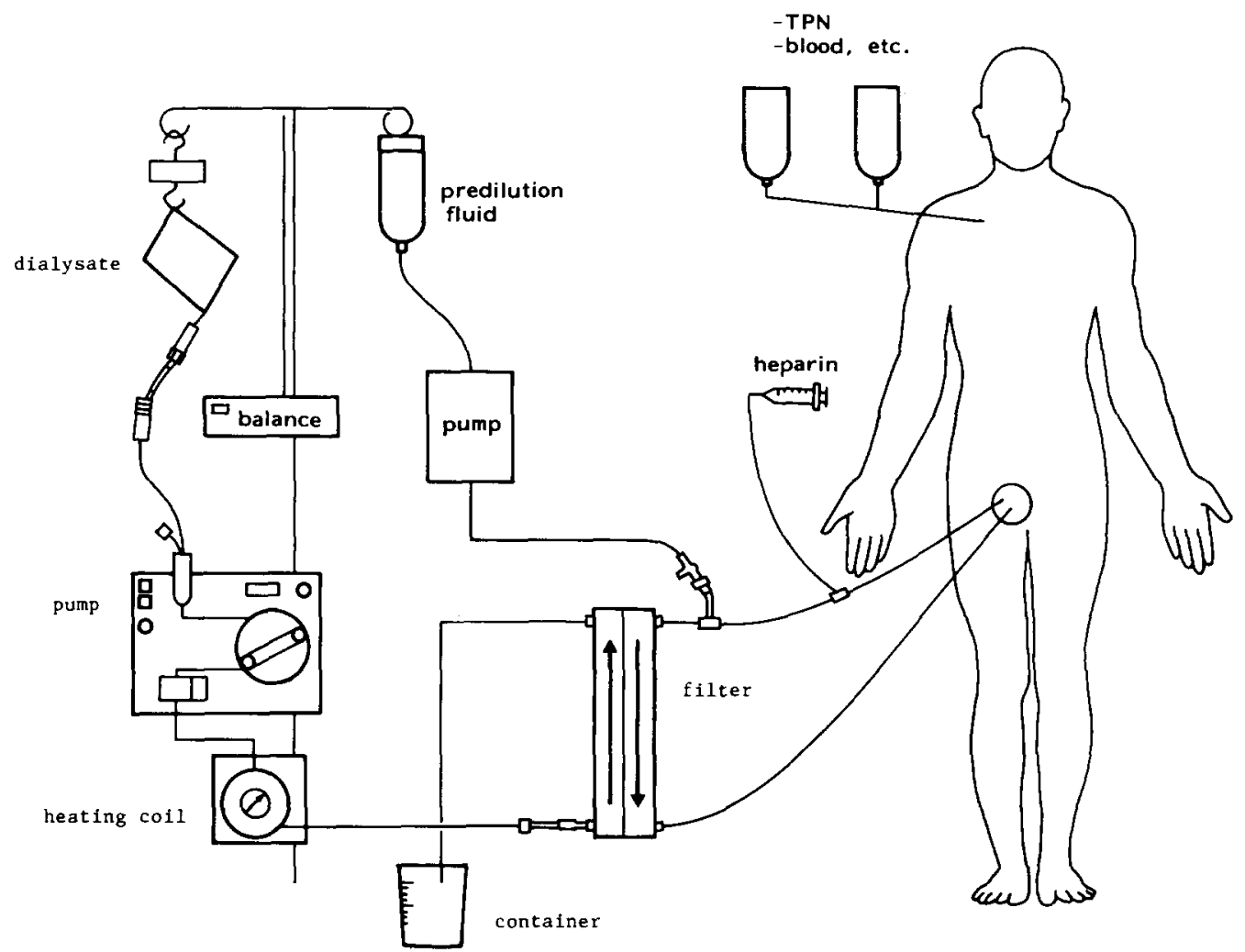

Fig. 1. Schematic representation of circuitry for CAVHD.

tained only with new filters in a laboratory setting. In the clinical setting, insight into the rate of solute removal is needed, both to determine the optimal dialysate flow rate and as a guide to concomitant drug therapy.

To enable the study of filter performance, especially regarding diffusive transport, under clinical conditions, we developed a new mathematical model of CAVHD. In this model, diffusive mass transfer coefficient, $K_{\mathrm{d}}$, is expressed as a function of measured blood and dialysate flow rates and solute concentrations and the rate of ultrafiltrate production. The present report concerns the derivation of this model.

\section{Description of the model}

The model was set up as a one-dimensional analysis of solute transport from plasma water to dialysate by simultaneous diffusion and convection.
The model applies to the countercurrent mode of blood and dialysate flows (Fig. 2). In this model the following assumptions have been made:

(1) The filter used consists of a bundle of hollow fibers through which plasma water flow is distributed homogeneously [1].

(2) The solute concentration varies axially with distance $(x)$ along the fiber length, while it is uniformly distributed radially [1]. Thus, diffusive solute transport results from a concentration gradient between blood and dialysate only. Because the axial solute transport in the filter by convection is much higher than by diffusion, axial diffusion is neglected in our model.

(3) The membrane permeabilities both for ultrafiltration and for diffusion are equal over the entire membrane length. During the use of the filter the permeability will decrease and it may cause that the permeability is no longer equal over the membrane length. No information about this effect is available. 


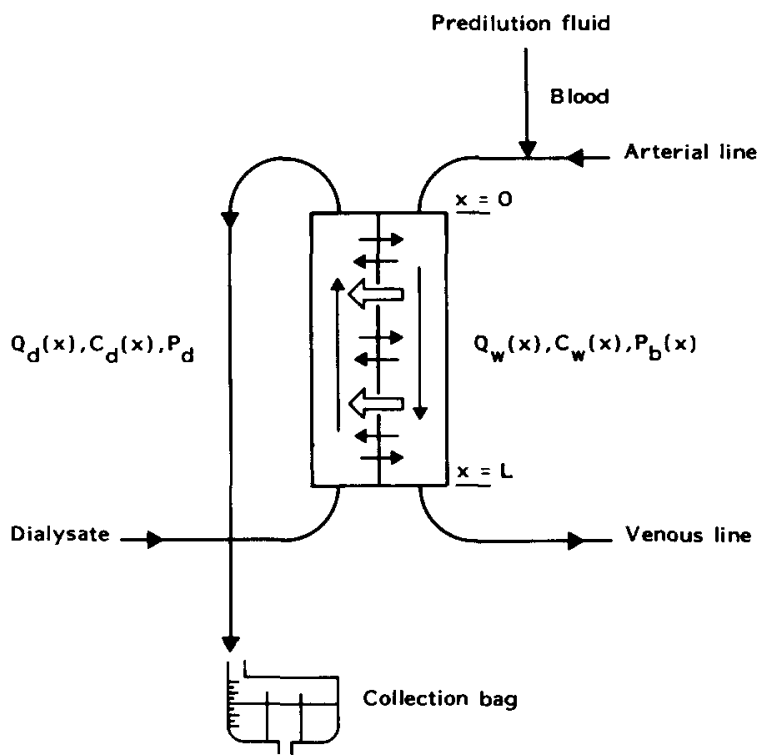

Fig. 2. Schematic representation of countercurrent transport of blood flow and dialysate flow. $x=0$ : blood (dialysate) inlet (outlet), $x=L$ : blood (dialysate) outlet (inlet).

(4) The transmembrane pressure gradient is equal along the membrane length. By this assumption convective clearance will be somewhat underestimated, as in reality, the transmembrane pressure gradient is highest at the filter blood inlet, where the plasma water solute concentration is highest.

(5) The oncotic pressure due to plasma proteins on the dialysate compartment is zero. Diameter of the pores of the filter membrane is smaller than those of the plasma proteins so that no plasma protein leakage from the blood compartment into the dialysate compartment can occur.

(6) The sieving coefficient of the solute is 1 . The solute dragged along by the plasma water flowing through the membrane can be reduced by an hindrance factor called the sieving coefficient of the solute, i.e. the ratio of its concentration in ultrafiltrate and to that in plasma water. We assume a value of 1 for the sieving coefficient which corresponds to that of urea.

(7) The solute concentration at the inlet of the dialysate compartment is zero. The solute concentration transferred from the blood compartment into the dialysate compartment at the blood outlet is negligible which means that the solute concentration can be accepted as zero at the inlet of the dialysate.

(8) The flow rates and solute concentrations are independent of time for a given set of measurements (steady state).

\subsection{The boundary conditions}

The boundary conditions are defined as follows (Fig. 2):

\begin{tabular}{|c|c|c|c|}
\hline & For & $\begin{array}{l}\text { at } x \\
=0\end{array}$ & $\begin{array}{l}\text { at } x \\
=L\end{array}$ \\
\hline Plasma water & & & \\
\hline flow rate & $Q_{w}(x)$ & $Q_{\mathrm{wi}}$ & $Q_{\text {wo }}$ \\
\hline Dialysate flow rate & $-Q_{\mathrm{d}}(x)$ & $Q_{\mathrm{do}}$ & $Q_{\mathrm{di}}$ \\
\hline $\begin{array}{l}\text { Solute concentration } \\
\text { in plasma water }\end{array}$ & $C_{\mathrm{w}}(x):$ & $C_{\mathrm{wi}_{\mathrm{i}}}$ & $C_{\mathrm{wo}}$ \\
\hline $\begin{array}{l}\text { Solute concentration } \\
\text { in dialysate }\end{array}$ & $C_{\mathrm{d}}(x):$ & $C_{\mathrm{do}}$ & $C_{\mathrm{di}}=0$ \\
\hline on the blood side & $P_{\mathrm{b}}(x):$ & $P_{\mathrm{i}}$ & $P_{\mathrm{o}}$ \\
\hline
\end{tabular}

where $i$ and o represent the inlet and outlet respectively. See Appendix for the definition of the symbols and units.

\subsection{Continuity equations}

Continuity on the blood side over a differential length $\mathrm{d} x$ of the dialyser is given by

$\mathrm{d} Q_{\mathrm{w}}(x)=-w J_{\mathrm{f}} \mathrm{d} x$

where $w=$ width, defined as $S / L, S$ the total membrane surface area, $L$ the membrane (or filter) length, and $J_{\mathrm{f}}$ is the ultrafiltrate volume flux.

The corresponding continuity equation on the dialysate side is

$\mathrm{d} Q_{\mathrm{d}}(x)=+w J_{\mathrm{f}} \mathrm{d} x$

On integrating equation (1) and equation (2) we obtain the axial distribution of flows on both sides of the dialyser:

$Q_{\mathrm{w}}(x)=Q_{\mathrm{wi}}-w J_{\mathrm{f}} x$

$Q_{\mathrm{d}}(x)=w J_{\mathrm{f}} x-Q_{\mathrm{do}}$ 
From the boundary conditions at $x=L$, it follows that

$Q_{\mathrm{wo}}=Q_{\mathrm{wi}}-S J_{\mathrm{f}}$

$Q_{\mathrm{di}}=Q_{\mathrm{do}}-S J_{\mathrm{f}}$

where the product $S \cdot J_{\mathrm{f}}$ is the net ultrafiltrate production rate, $Q_{\mathrm{f}}$ :

$Q_{\mathrm{f}}=S \cdot J_{\mathrm{f}}$

\subsection{Ultrafiltration flux $J_{\mathrm{f}}$}

The ultrafiltration volume flux of plasma water is given by

$J_{\mathrm{f}}=L_{\mathrm{p}}\left(\frac{1}{2}\left(P_{\mathrm{i}}+P_{\mathrm{o}}\right)-P_{\mathrm{d}}-\pi_{p}\right)=L_{\mathrm{p}} \cdot \mathrm{TMP}$

where $L_{\mathrm{p}}$ is the hydraulic membrane permeability, $P_{\mathrm{i}}$ is the prefilter hydraulic pressure, $P_{\mathrm{o}}$ is the postfilter hydraulic pressure, $P_{\mathrm{d}}$ is the average pressure on the dialysate side calculated as the product of 0.74 (a conversion factor to express $P_{\mathrm{d}}$ in $\mathrm{mm} \mathrm{Hg}$ ) times the vertical distance (in centimeters) of the dialyser to the collection bag, TMP is the transmembrane pressure, and $\pi_{p}$ the plasma oncotic pressure defined in terms of the plasma protein concentration, $C_{p}$, is according to the Landis-Pappenheimer formula [6]:

$\pi_{p}=2.1 C_{\mathrm{p}}+0.16 C_{\mathrm{p}}^{2}+0.009 C_{\mathrm{p}}^{3}$

On substituting equation (8) in equation (7), we obtain the membrane hydraulic permeability:

$L_{\mathrm{p}}=\frac{Q_{\mathrm{f}}}{S \cdot \mathrm{TMP}}$

\subsection{Conservation equations}

A mass balance for a particular solute species over a differential length $\mathrm{d} x$ of the filter may be written as

$$
\begin{aligned}
& \frac{d\left[Q_{\mathrm{w}}(x) C_{\mathrm{w}}(x)\right]}{\mathrm{d} x} \\
& \quad=-w J_{\mathrm{f}} C_{\mathrm{w}}(x)-w K_{\mathrm{d}}\left[C_{\mathrm{w}}(x)-C_{\mathrm{d}}(x)\right]
\end{aligned}
$$

for the blood side, and as

$$
\begin{aligned}
& \frac{\mathrm{d}\left[Q_{\mathrm{d}}(x) C_{\mathrm{d}}(x)\right]}{\mathrm{d} x} \\
& \quad=w J_{\mathrm{f}} C_{\mathrm{w}}(x)+w K_{\mathrm{d}}\left[C_{\mathrm{w}}(x)-C_{\mathrm{d}}(x)\right]
\end{aligned}
$$

for the dialysate side. In these equations $K_{\mathrm{d}}$ is the mass transfer coefficient of the membrane for the diffusive solute transport. $K_{\mathrm{d}}$ is a measure of diffusive membrane permeability which, however, cannot be determined directly.

\subsection{Derivation of the concentration profiles}

We may write:

$$
\begin{aligned}
& \frac{\mathrm{d}\left[Q_{\mathrm{w}}(x) C_{\mathrm{w}}(x)\right]}{\mathrm{d} x} \\
& =Q_{\mathrm{w}}(x) \frac{\mathrm{d} C_{\mathrm{w}}(x)}{\mathrm{d} x}+C_{\mathrm{w}}(x) \frac{\mathrm{d} Q_{\mathrm{w}}(x)}{\mathrm{d} x}
\end{aligned}
$$

On substituting equation (1) in equation (13) and making the resulting expression equal to the right-hand side of equation (11) we obtain:

$\frac{\mathrm{d} C_{\mathrm{w}}(x)}{\mathrm{d} x}=\frac{-w K_{\mathrm{d}} \delta C(x)}{Q_{\mathrm{w}}(x)}$

where $\delta C(x)=C_{\mathrm{w}}(x)-C_{\mathrm{d}}(x)$, the concentration difference between the blood side and dialysate side.

In a similar way, we find from the combination of equations (12) and (2) a corresponding equation for the dialysate side:

$\frac{\mathrm{d} C_{\mathrm{d}}(x)}{\mathrm{d} x}=\frac{w\left(J_{\mathrm{f}}+K_{\mathrm{d}}\right) \delta C(x)}{Q_{\mathrm{d}}(x)}$

On subtracting equation (15) from equation (14), we obtain:

$$
\frac{\mathrm{d} \delta C(x)}{\delta C(x)}=-\frac{w K_{\mathrm{d}} \mathrm{d} x}{Q_{\mathrm{w}}(x)}-\frac{w\left(K_{\mathrm{d}}+J_{\mathrm{f}}\right) \mathrm{d} x}{Q_{\mathrm{d}}(x)}
$$

and elimination of $\mathrm{d} x$ by using equations (1) and (2) gives:

$$
\frac{\mathrm{d} \delta C(x)}{\delta C(x)}=n \frac{\mathrm{d} Q_{\mathrm{w}}(x)}{Q_{\mathrm{w}}(x)}-(n+1) \frac{\mathrm{d} Q_{\mathrm{d}}(x)}{Q_{\mathrm{d}}(x)}
$$


with

$n=\frac{K_{\mathrm{d}}}{J_{\mathrm{f}}}$

Integrating equation (17) along the membrane length we obtain:

$$
\begin{aligned}
\operatorname{Ln}[\delta C(x)]= & n \operatorname{Ln}\left[Q_{\mathrm{w}}(x)\right] \\
& -(n+1) \operatorname{Ln}\left[-Q_{\mathrm{d}}(x)\right] \\
& +\operatorname{Ln}\left(-A_{1}\right)
\end{aligned}
$$

where $A_{1}$ is an integration constant. Here $Q_{\mathrm{d}}(x)$ and $A_{1}$ are considered negative numbers, and the minus sign appears because of the countercurrent dialysate flow direction.

Elimination of the $\mathrm{Ln}$ function yields

$\delta C(x)=-A_{1}\left[Q_{\mathrm{w}}(x)\right]^{n}\left[-Q_{\mathrm{d}}(x)\right]^{-(n+1)}$

The condition of conservation of solute, both in blood and dialysate, implies

$Q_{\mathrm{w}}(x) C_{\mathrm{w}}(x)+Q_{\mathrm{d}}(x) C_{\mathrm{d}}(x)=A_{2}$

where $A_{2}$ is a constant. Multiplying equation (20) by $Q_{\mathrm{w}}(x)$ and by $Q_{\mathrm{d}}(x)$ respectively we find

$$
\begin{aligned}
& Q_{\mathrm{w}}(x) \delta C(x) \\
& \quad=-A_{1}\left[Q_{\mathrm{w}}(x)\right]^{n+1}\left[-Q_{\mathrm{d}}(x)\right]^{-(n+1)}
\end{aligned}
$$

and

$Q_{\mathrm{d}}(x) \delta C(x)=A_{1}\left[Q_{\mathrm{w}}(x)\right]^{n}\left[-Q_{\mathrm{d}}(x)\right]^{-n}$

Subtraction of equation (22) from equation (21) gives

$$
\begin{aligned}
C_{\mathrm{d}}(x)= & \frac{1}{Q_{\mathrm{w}}(x)+Q_{\mathrm{d}}(x)} \\
& \times\left\{A_{2}+A_{1}\left[Q_{\mathrm{w}}(x)\right]^{n+1}\right. \\
& \left.\times\left[-Q_{\mathrm{d}}(x)\right]^{-(n+1)}\right\}
\end{aligned}
$$

Addition of equation (23) to equation (21) yields

$$
\begin{aligned}
C_{\mathrm{w}}(x)= & \frac{1}{Q_{\mathrm{w}}(x)+Q_{\mathrm{d}}(x)} \\
& \times\left\{A_{2}+A_{1}\left[Q_{\mathrm{w}}(x)\right]^{n}\left[-Q_{\mathrm{d}}(x)\right]^{-n}\right\}
\end{aligned}
$$

From equations (3) and (4) it follows that

$$
Q_{\mathrm{w}}(x)+Q_{\mathrm{d}}(x)=Q_{\mathrm{wi}}-Q_{\mathrm{do}}
$$

Because of the boundary conditions at $x=0$, we obtain

$$
\begin{aligned}
& A_{1}=\left(C_{\mathrm{do}}-C_{\mathrm{wi}}\right)\left(Q_{\mathrm{do}}\right)^{n+1}\left(Q_{\mathrm{wi}}\right)^{-n} \\
& A_{2}=Q_{\mathrm{wi}} C_{\mathrm{wi}}-Q_{\mathrm{do}} C_{\mathrm{do}}
\end{aligned}
$$

Substitution of $A_{1}$ and $A_{2}$, and equations (3-6, $26)$ in equation (24) and in equation (25) respectively yields the concentration profile of the solute on the blood side:

$$
\begin{aligned}
& C_{\mathrm{w}}(x) \\
& =\frac{Q_{\mathrm{wi}} C_{\mathrm{wi}}-Q_{\mathrm{do}} C_{\mathrm{do}}}{Q_{\mathrm{wi}}-Q_{\mathrm{do}}}+\frac{Q_{\mathrm{do}}\left(C_{\mathrm{do}}-C_{\mathrm{wi}}\right)}{Q_{\mathrm{wi}}-Q_{\mathrm{do}}}[Y(x)]^{n}
\end{aligned}
$$

with

$$
Y(x)=\left(1-\frac{Q_{\mathrm{f}}}{Q_{\mathrm{wi}}} \frac{x}{L}\right) /\left(1-\frac{Q_{\mathrm{f}}}{Q_{\mathrm{do}}} \frac{x}{L}\right)
$$

and on the dialysate side:

$$
\begin{aligned}
C_{\mathrm{d}}(x)= & \frac{Q_{\mathrm{wi}} C_{\mathrm{wi}}-Q_{\mathrm{do}} C_{\mathrm{do}}}{Q_{\mathrm{wi}}-Q_{\mathrm{do}}} \\
& +\frac{Q_{\mathrm{wi}}\left(C_{\mathrm{do}}-C_{\mathrm{wi}}\right)}{Q_{\mathrm{wi}}-Q_{\mathrm{do}}}[Y(x)]^{n+1}
\end{aligned}
$$

\subsection{Diffusive mass transfer coefficient $K_{\mathrm{d}}$}

Since the dialysate solute concentration at the inlet is zero $\left(C_{\mathrm{di}}=0\right)$, further elaboration of equa- 


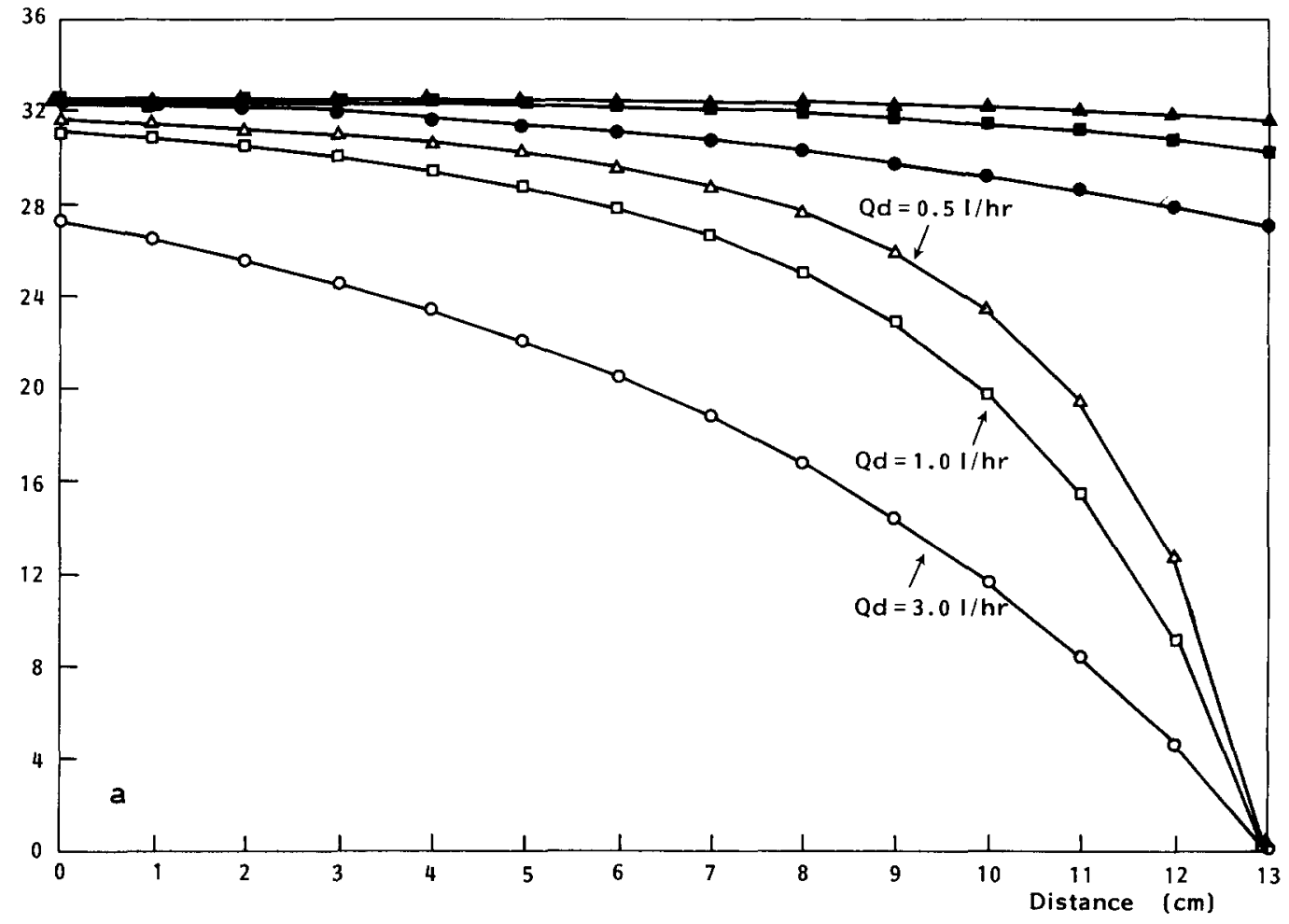

Concentration ( $\mathrm{mmol} / \mathrm{l}$ )

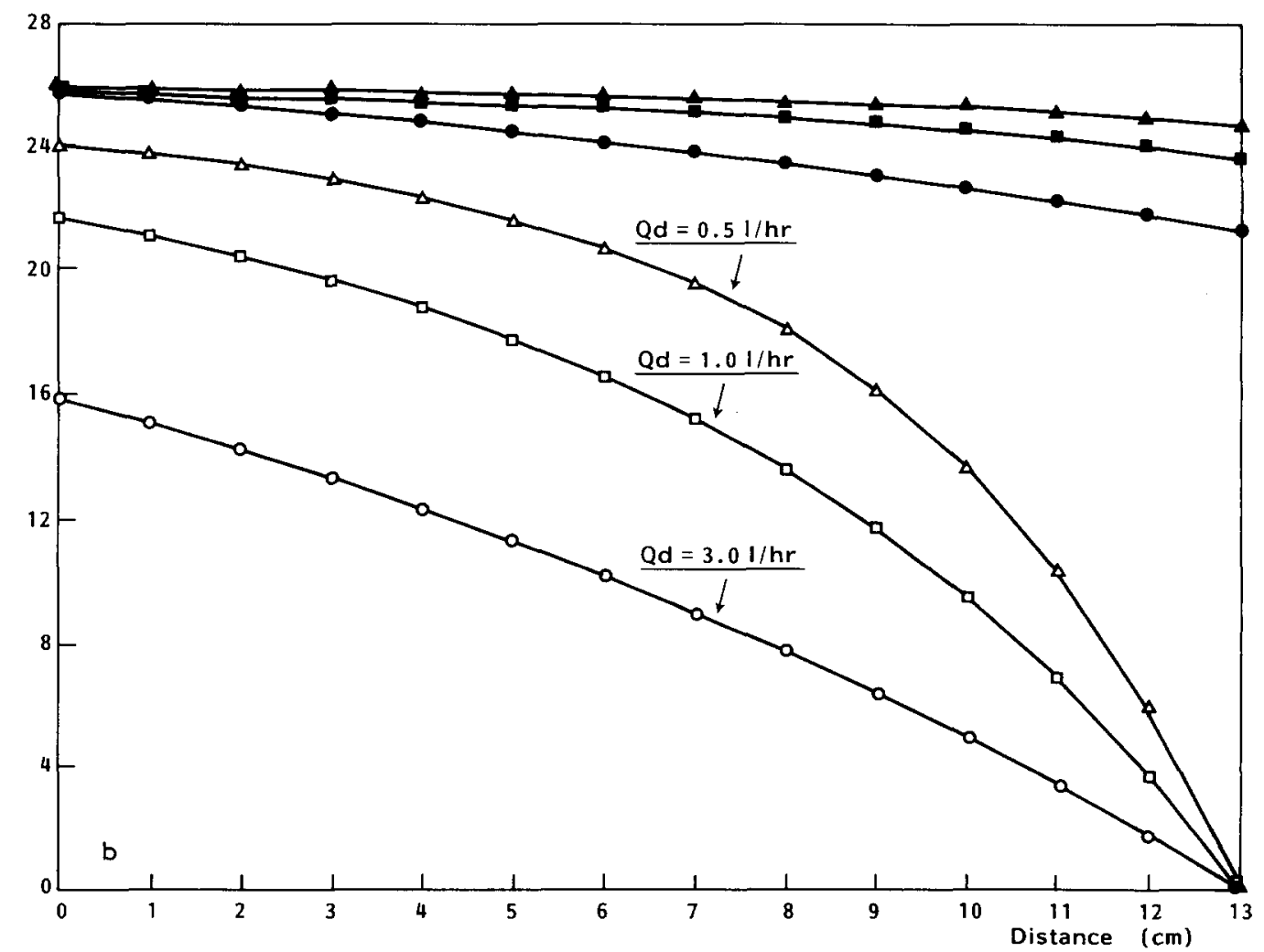




\section{TABLE 1}

Data obtained from two different hemofilters. In case 1 the filter had been used for $1 \mathrm{~h}$, in case 2 for 3 days. The errors of the measured or calculated quantities in this table are considered to be not relevant at this stage. Clc: clearance by convection; Cld: clearance by diffusion. Furthermore see Appendix for the definition of symbols and units.

\begin{tabular}{|c|c|c|c|c|c|c|c|}
\hline \multicolumn{4}{|l|}{ Case 1} & \multicolumn{4}{|c|}{ Case 2} \\
\hline$\overline{Q_{\mathrm{bi}}}$ & $Q_{\mathrm{di}}$ & $Q_{f}$ & TMP & $Q_{\mathrm{bi}}$ & $Q_{\mathrm{di}}$ & $Q_{\mathrm{f}}$ & TMP \\
\hline 264 & 7.3 & 18.0 & 78.4 & 199 & 8.5 & 6.2 & 75.5 \\
\hline 264 & 1.0 & 18.0 & 78.4 & 199 & 18.0 & 6.2 & 75.5 \\
\hline 264 & 35.5 & 18.0 & 78.4 & 199 & 35.0 & 6.2 & 75.5 \\
\hline 264 & 51.0 & 18.0 & 78.4 & 199 & 54.0 & 6.2 & 75.5 \\
\hline$\overline{\mathrm{Clc}}$ & Cld & $K_{\mathrm{d}}$ & $L_{\mathrm{p}}$ & $\mathrm{Clc}$ & Cld & $K_{\mathrm{d}}$ & $L_{\mathrm{p}}$ \\
\hline 19.0 & 7.0 & 58.2 & 0.38 & 6.6 & 7.1 & 29.1 & 0.14 \\
\hline 18.8 & 17.7 & 117.4 & 0.38 & 6.5 & 13.8 & 45.5 & 0.14 \\
\hline 18.3 & 33.1 & 165.5 & 0.38 & 6.4 & 21.5 & 57.3 & 0.14 \\
\hline 17.9 & 43.0 & 173.5 & 0.38 & 6.2 & 30.8 & 78.8 & 0.14 \\
\hline
\end{tabular}

tion (31) yields the following expression for the ratio of the diffusive mass transfer coefficient to the filtrate volume flux:

$$
\frac{K_{\mathrm{d}}}{J_{\mathrm{f}}}=\frac{\operatorname{Ln}\left(\frac{Q_{\mathrm{do}} C_{\mathrm{do}}-Q_{\mathrm{wi}} C_{\mathrm{wi}}}{Q_{\mathrm{wi}} C_{\mathrm{do}}-Q_{\mathrm{wi}} C_{\mathrm{wi}}}\right)}{\operatorname{Ln}\left(\frac{Q_{\mathrm{wo}} Q_{\mathrm{do}}}{Q_{\mathrm{wi}} Q_{\mathrm{di}}}\right)}-1
$$

As $J_{\mathrm{f}}$ is calculated as $Q_{\mathrm{f}} / S$ (equation (7)), this expression may be used to calculate $K_{\mathrm{d}}$ from blood and dialysate flow rates and solute concentrations.

\subsection{Clearance}

Clearance of a solute is a clinical term. It is defined as the ratio of the amount of solute removed per unit of time to its plasma concentration at the blood inlet $\left(C_{\mathrm{pi}}\right)$, or the solute mass transfer rate divided by its plasma concentration $\left(C_{\mathrm{pi}}\right)$ at the blood inlet. Thus, with $C_{\mathrm{di}}=0$, clearance of the solute is given by:

$\mathrm{Cl}=\frac{Q_{\mathrm{do}} C_{\mathrm{do}}}{C_{\mathrm{pi}}}$

When $J_{\mathrm{f}}$ and $K_{\mathrm{d}}$ are known (see equation (8) and equation (32)), the solute mass transfer rate, in moles per unit of time, may be calculated by integrating equation (12) over the membrane length. Equation (33) becomes:

$\mathrm{Cl}=\frac{1}{C_{\mathrm{pi}}}\left\{\int_{0}^{L} w J_{\mathrm{f}} C_{\mathrm{w}}(x) \mathrm{d} x\right.$

$$
\left.+\int_{0}^{L} w K_{\mathrm{d}}\left[C_{\mathrm{w}}(x)-C_{\mathrm{d}}(x)\right] \mathrm{d} x\right\}
$$

The first term on the right-hand side of equation (34) represents the clearance by convective mass transfer and the second term the clearance by diffusive mass transfer.

Fig. 3. (a) Concentration profiles of urea in blood (curves with closed symbols) and in dialysate (curves with open symbols) as a function of axial position of hemofilter are shown for different dialysate flow rates (approximated values) for a new hemofilter (0.6 $\mathrm{m}^{2}$ AN-69, Multiflow-60, Hospal, France, after being used for $1 \mathrm{~h}$ ) with relatively high membrane permeability (see Table 1, case 1). (b) Concentration profiles of urea in blood (curves with closed symbols) and in dialysate (curves with open symbols) as a function of axial position of hemofilter are shown for different dialysate flow rates for a second hemofilter $\left(0.6 \mathrm{~m}^{2} \mathrm{AN}-69\right.$, Multiflow-60, Hospal, France, after being used for 3 days) with relatively low membrane permeability (see Table 1, case 2). 


\section{Application of the model to clinical data}

The model equations were applied to numerical data for urea, obtained from patients treated with CAVHD with $0.6 \mathrm{~m}^{2}$ AN-69 capillary dialysers (Multiflow-60, Hospal, France). Blood flow rate was determined by air bubble displacement over a certain length of tubing. The dialysate flow and substitution fluid infusion rates were determined by weighing the fluid bag. The net rate of the ultrafiltration production was measured by timed ultrafiltrate collection.

The plasma water flow rate at the inlet $\left(Q_{\mathrm{wi}}\right)$ was calculated by the formula:

$$
Q_{\mathrm{wi}}=Q_{\mathrm{bi}}(1-\mathrm{Ht})\left(1-\alpha C_{\mathrm{prot}}\right)+Q_{\mathrm{bi}} f \mathrm{Ht}+Q_{\mathrm{pred}}
$$

where $Q_{\mathrm{bi}}$ is the blood flow rate at the inlet, $\mathrm{Ht}$ is the hematocrit, $\alpha C_{\mathrm{prot}}$ is the protocrit (calculated from protein concentration $\left(C_{\text {prot }}\right)$ by the factor $\alpha=0.00107 \mathrm{l} / \mathrm{g}[1], f$ is the fractional volume distribution of solute in blood cells ( $f=0.8$ for urea [2]) and $Q_{\text {pred }}$ is the rate of infusion of substitution fluid ('pre-dilution') into the arterial line.

The plasma water solute concentration at the inlet, $C_{\mathrm{wi}}$, was calculated by:

$$
C_{\mathrm{wi}}=C_{\mathrm{pi}} /\left(1-\alpha C_{\text {prot }}\right)
$$

Data for two sets of measurements are given in Table 1. The first (case 1) was obtained with a new filter, characterized by a relatively high rate of ultrafiltrate production. The second (case 2) was obtained with a filter that had been used for 3 days. Deterioration of the filter conditions is reflected in both a lower value of the hydraulic permeability $L_{\mathrm{p}}$ and lower values of $K_{\mathrm{d}}$.

The corresponding concentration profiles, as calculated by our model equations, and their dependence on dialysate flow rate are shown in Fig. $3 a$ and $b$.

A detailed account on the clinical applicability of this model will be given in a separate publication.

\section{Discussion}

Our model is the first detailed mathematical description of solute transport in CAVHD. It was meant as a tool to study the impact of variables such as blood and dialysate flow rates, ultrafiltration and the deterioration of membrane conditions with continued use of the filter on solute transport. In clinical practice, as filtration rate has to be monitored, convective clearance is easily determined. There is, however, a need for methods to estimate diffusive and total solute transport. Therefore we focused on the parameter $K_{\mathrm{d}}$, which represents the mass transfer coefficient of the filter membrane for diffusion.

The anticipated differences between CAVHD and conventional hemodialysis and hemodiafiltration are borne out, first, by the demonstration of the curvilinear solute concentration profiles in the dialysate compartment (Fig. $3 a$ and $b$ ). Second, filter performance had indeed decreased appreciably after 3 days of use (Table 1). It must be realized that $K_{\mathrm{d}}$ cannot be measured directly, but is calculated on the basis of the resulting solute transport, assuming a constant membrane surface area. A decrease in $K_{\mathrm{d}}$ may therefore result either from a decrease in membrane permeability or from a decrease in effective membrane surface area. The latter may be due to clotting of fibers. It might also be due to unequal distribution of the dialysate over the dialysate compartment, which is not unlikely to occur at very low dialysate flow rates. This influence of dialysate flow rate on $K_{\mathrm{d}}$ was not recognized by Pallone et al. [8].

The model equations apply to solutes with a sieving coefficient of 1 . This condition is likely to be met for most solutes that are considered to contribute to the uremic state. However, when considering drugs, protein binding and its influence on sieving would have to be taken into account. We intend to elaborate the model further in this respect.

Ultrafiltration was considered constant along the membrane length. In reality, due to the axial pressure drop in the blood compartment, ultrafiltration will diminish along the length of the dialyser. In view of the relatively small decrease in solute concentration in the blood compartment, 
however, this will have minor influence on calculated convective transport (Fig. $3 a$ and $b$ ). A similar conclusion was reached by Jaffrin et al. [5].

\section{References}

[1] C.K. Colton, L.W. Henderson, C.A. Ford and M.J. Lysaght, Kinetics of hemodiafiltration. I. In vitro transport characteristics of a hollow-fiber blood ultrafilter, J. Lab. Clin. Invest. 85 (1975) 355-371.

[2] C.K. Colton, K.A. Smith, E.W. Merrill and J.M. Reece, Diffusion of organic solutes in stagnant plasma and red cell suspensions, Chem. Eng. Prog. Symp. Ser. No. 66, 99 (1970) 85-100.

[3] J.A. van Geelen, Hemodiafiltration, Simultaneous Application of Hemodialysis and Hemofiltration. MD Thesis (University of Limburg, Maastricht, 1983).

[4] J.A. van Geelen, H.H. Vincent and M.A.D.H. Schalekamp, Continuous arteriovenous haemofiltration and haemodiafiltration in acute renal failure, Nephrol. Dialysis Transplant. 2 (1988) 181-186.
[5] M.Y. Jaffrin, B.B. Gupta and J.M. Malbrancq, A one-dimensional model of simultaneous hemodialysis and ultrafiltration with highly permeable membranes, J. Biomech. Eng. 103 (1981) 261-266.

[6] E.M. Landis and J.R. Pappenheimer, Exchange of substances through the capillary wall, in: Handbook of Physiology, Sect. 2, Vol. 2, Circulation, Chapt. 29, pp. 962-1034 (American Physiologic Society, Washington, DC, 1963).

[7] E.P. Paganini, Acute Continuous Renal Replacement Therapy (Martinus Nijhoff Publishing, Boston, MA, 1986).

[8] T.L. Pallone, S. Hyver and J. Petersen, The simulation of continuous arteriovenous hemodialysis with a mathematical model, Kidney Int. 35 (1989) 125-133.

[9] J.A. Sargent, F.A. Gotch, Principles and biophysics of dialysis, in: Replacement of Renal Function by Dialysis. eds. W. Drukker, F.M. Parsons and J.F. Maher (Martinus Nijhoff Medical Division, The Hague - Boston, MA London, 1978).

[10] M.H. Sigler and B.P. Teehan, Solute transport in continuous hemodialysis. A new treatment for acute renal failure. Kidney Int. 32 (1987) 562-571. 


\section{Appendix}

Definition of symbols and units

\begin{tabular}{|c|c|c|}
\hline Symbols & Definition & Units \\
\hline$Q_{\mathrm{b}}$ & flow rate of blood & $\mathrm{ml} / \mathrm{min}$ \\
\hline$Q_{w}$ & flow rate of plasma water & $\mathrm{ml} / \mathrm{min}$ \\
\hline$Q_{\text {pred }}$ & flow rate of substitution fluid infusion & $\mathrm{ml} / \mathrm{min}$ \\
\hline$Q_{\mathrm{d}}$ & flow rate of dialysate & $\mathrm{ml} / \mathrm{min}$ \\
\hline$Q_{\mathrm{f}}$ & flow rate of ultrafiltrate & $\mathrm{ml} / \mathrm{min}$ \\
\hline$C_{\mathrm{p}}$ & concentration of solute in plasma & $\mathrm{mmol} / 1$ \\
\hline$C_{\mathrm{w}}$ & concentration of solute in plasma water & $\mathrm{mmol} / 1$ \\
\hline$C_{\mathrm{d}}$ & concentration of solute in dialysate & $\mathrm{mmol} / 1$ \\
\hline$\delta C(x)$ & concentration difference between the plasma water and dialysate & $\mathrm{mmol} / 1$ \\
\hline TMP & transmembrane pressure gradient & $\mathrm{mm} \mathrm{Hg}$ \\
\hline$P_{\mathrm{b}}$ & hydraulic pressure on the blood side & $\mathrm{mm} \mathrm{Hg}$ \\
\hline$P_{\mathrm{i}}$ & hydraulic pressure at the blood inlet & $\mathrm{mm} \mathrm{Hg}$ \\
\hline$P_{\mathrm{o}}$ & hydraulic pressure at the blood outlet & $\mathrm{mm} \mathrm{Hg}$ \\
\hline$P_{\mathrm{d}}$ & average pressure on the dialysate side & $\mathrm{mm} \mathrm{Hg}$ \\
\hline$\pi_{p}$ & oncotic pressure on the blood side & $\mathrm{mm} \mathrm{Hg}$ \\
\hline$L_{\mathrm{p}}$ & hydraulic membrane permeability & $\mu \mathrm{m} /(\mathrm{min} \cdot \mathrm{mm} \mathrm{Hg})$ \\
\hline$J_{\mathrm{f}}$ & filtrate volume flux & $\mu \mathrm{m} / \mathrm{min}$ \\
\hline$K_{\mathrm{d}}$ & diffusive mass transfer coefficient & $\mu \mathrm{m} / \mathrm{min}$ \\
\hline $\mathrm{Cl}$ & clearance & $\mathrm{ml} / \mathrm{min}$ \\
\hline $\mathrm{Cld}$ & clearance by diffusion & $\mathrm{ml} / \mathrm{min}$ \\
\hline $\mathrm{Clc}$ & clearance by convection & $\mathrm{ml} / \mathrm{min}$ \\
\hline$S$ & total membrane surface area & $\mathrm{m}^{2}$ \\
\hline$L$ & membrane length & $\mathbf{m}$ \\
\hline$w$ & membrane width $(=S / L)$ & $\mathrm{m}$ \\
\hline$x$ & axial coordinate along the dialyser & $\mathrm{m}$ \\
\hline $\mathrm{d} x$ & differential length & $\mathrm{m}$ \\
\hline $\mathrm{i}$ & inlet & \\
\hline o & outlet & \\
\hline$A_{1}, A_{2}$ & constants & \\
\hline \multirow[t]{2}{*}{$n$} & ratio of the diffusive mass transfer & \\
\hline & coefficient to the plasma water volume flux & \\
\hline$Y(x)$ & a function of the variable $x$ & \\
\hline $\mathrm{Ht}$ & hematocrit (fractional volume of blood cells in whole blood) & \\
\hline$C_{\text {prot }}$ & concentration of protein in plasma & $\mathrm{g} / \mathbf{l}$ \\
\hline$\alpha$ & coefficient to calculate protocrit & \\
\hline & (fractional volume of protein in plasma) $\alpha=0.00107$ (ref. [1,9]) & $1 / g$ \\
\hline$f$ & $\begin{array}{l}\text { fractional volume distribution of solute } \\
\text { in blood cells } f=0.8 \text { for urea (ref. [2]) }\end{array}$ & \\
\hline
\end{tabular}

